\title{
Morphology and optical properties of $\alpha$-Si:Y films obtained by the electron-beam evaporation method
}

\author{
T.V. Semikina \\ Department of Environmental \& Material Engineering, \\ Teikyo University of Science \& Technology, \\ 2525 Yatsusawa, Uenohara-machi, Kitatsuru-gun, \\ Yamanashi-pref., 409-0193 Japan \\ E-mail: semikina@edd.ntu-kpi.kiev.ua,tanyasemikina@rambler.ru
}

\begin{abstract}
This paper presents the results of AFM, Raman, IR spectroscopy and ellipsometry of $\alpha$-Si:Y films prepared by electron-beam evaporation. The influence of the type and temperature of substrates, as well as the evaporation rate on film morphology, composition and optical properties are studied. The evaporation rate increase allows to enhance the growth of films on $p$-Si up to $0.1 \mu \mathrm{m} / \mathrm{min}$. The obtained $\alpha$-Si:Y films possess an amorphous structure with a small amount of nanocrystalline inclusions. The formation of nanocrystalline inclusions could be generated by $\mathrm{SiH}_{\mathrm{x}}$, peaks of which are clearly pronounced at 650,890 and $2125 \mathrm{~cm}^{-1}$ in the IR spectrum or yttrium impurities. The ellipsometry results show that $\alpha$-Si:Y films have the high absorption coefficient, refraction index is 3.4 at the wavelength $\lambda=620 \mathrm{~nm}$. The optical bandgap drops from 2.0 to $1.17 \mathrm{eV}$ when the substrate temperature increases $\left(140\right.$ to $\left.300{ }^{\circ} \mathrm{C}\right)$.
\end{abstract}

Keywords: $\alpha$-Si:Y amorphous film, electron-beam evaporation, IR and Raman spectroscopy, optical properties.

Manuscript received 10.06.05; accepted for publication 25.10.05.

\section{Introduction}

The films based on amorphous silicon are under research attention for more than 20 years. In comparison with another semiconductors, this interest is stimulated by the fact that $\alpha-\mathrm{Si}$ has such inspiring properties as high photoconductivity, high absorption coefficient and ability of effective doping [1, 2]. Nowadays, the hydrogenated amorphous silicon films $\alpha-\mathrm{Si}: \mathrm{H}$ are used as an active layer in thin film transistors of switching network in liquid crystal displays. Solar cells applied in calculators are also covered with $\alpha-\mathrm{Si}: \mathrm{H}$ film. These films are used in color sensors [3]. However, the $\alpha-\mathrm{Si}: \mathrm{H}$ photoelectrical properties degrade under illumination, which is known as the Staebler-Wronsky effect [2]. As a result, the efficiency of solar cells with $\alpha$-Si:H film drops from $10 \%$ to less than $8 \%$ after long illumination duration. That is why there are several actual tasks: to reduce film degradation in the course of illumination, to decrease the amount of photoinduced recombination centers and increase the carrier charge mobility. There are various methods to resolve the mentioned tasks. For example, the solar cells covered with $\alpha$-Si:H layer of $0.1 \mu \mathrm{m}$ thickness do not demonstrate the photoelectrical properties degradation under illumination process. However, their efficiency was considerably less (4\%) because of decreased sun radiation absorption [3]. Recently, the more perspective direction became deposition of $\alpha-\mathrm{Si}: \mathrm{H}$ films containing inclusions of silicon nanocrystalline phase (nc-Si) in amorphous matrix. The encouraging feature of this material is based on higher photosensivity and electrical characteristics stability of $\alpha$-Si $\langle\mathrm{nc}-\mathrm{Si}\rangle$ films as compared to homogenous amorphous films $[2,4]$. At the same time, $\alpha-\mathrm{Si}\langle\mathrm{nc}-\mathrm{Si}\rangle$ films are interesting objects of investigation in the field of semiconductor thin film physics. It is known that amorphous films with micro- and nanocrystalline composition have bigger defect density in comparison with homogenous films, which should lead to a decrease in photoconductivity [5]. However, in practice the $\alpha$-Si $\langle$ nc-Si $\rangle$ film photoconductivity is higher by an order of magnitude than that of amorphous silicon films [6]. There is no commonly adopted explanation of this fact $[6,7]$.

In this work, the issue of high film photosensitivity and stability of their electrical characteristics is resolved by development of deposition technology for amorphous silicon films with yttrium addition $\alpha-\mathrm{Si}: \mathrm{Y}$. This new 
elaboration is based on the idea to exclude hydrogen from the technological process. As known [2], hydrogen escape from film composition is the main reason of instability in photoelectrical characteristics. The amorphous silicon-yttrium films presented in this paper are unique new objects that don't have analogs in world research. In our previous investigations $[8,9]$ of $\alpha-\mathrm{Si}: \mathrm{Y}$ films photoelectrical characteristics and photosensitivity, the optimal concentration of yttrium $10 \pm 2 \%$ was chosen. At this concentration, the dark conductivity had its minimum and was equal $\sigma_{\min }=10^{-11} \Omega^{-1} \mathrm{~cm}^{-1}$, and photoconductivity at the wavelength $\lambda=0.1 \mu \mathrm{m}$ reached its maximal value $\sigma_{\text {photocond }}=10^{-5} \Omega^{-1} \mathrm{~cm}^{-1}$. Moreover, at film exposition during 2000 hours the photoelectrical characteristic degradation was only $4-5 \%$. The first preliminary explanation of this great result was based on the assumptions that yttrium creates the photoactive centers that are responsible for high film photosensitivity, while the absence of hydrogen in the film structure provides the high characteristics stability. To elucidate the issues of the film composition and morphology, determination of such important characteristics as absorption value and optical width of the bandgap, the measurements by using optical and atomic force microscopy, ellipsometry, infrared and Raman spectroscopy were done.

\section{Technology of deposition}

Thin amorphous silicon-yttrium films were obtained by electron-beam evaporation of specially prepared alloys by using UVN-74P3 equipment with electron-beam evaporator of IL-5 type.

Crushed powder of monocrystalline silicon with yttrium where yttrium consists $10 \%$ relatively to silicon were put into a water-cooled crucible of electron-beam evaporator. To get the homogenous target composition, powders were alloyed in a chamber under vacuum $5 \cdot 10^{-6}$ Torr. The target evaporation was carried out for $7-8$ min onto the $n$-and $p$-type $\mathrm{Si}$ substrates. The evaporation rate was varied via changing of the beam evaporator emission current. All the technological conditions are summarized in Table.

The influence of the substrate conductivity type on the film properties, optimal substrate temperature and evaporation rate were studied in this work.

\subsection{Results of optical and atomic force microscopy}

From $\alpha$-Si:Y films images obtained using the optical microscope (Fig. 1), it is seen that films have an amorphous structure. These images are very close to the results of electron microscopy of amorphous $\alpha-\mathrm{Si}: \mathrm{H}$ films with small number of nanocrystalline inclusions that were prepared by the chemical vapor deposition method [7]. Both in the work [7] and in presented images, one can see dark points. These points can be interpreted as the film defects or graphite inclusions. The

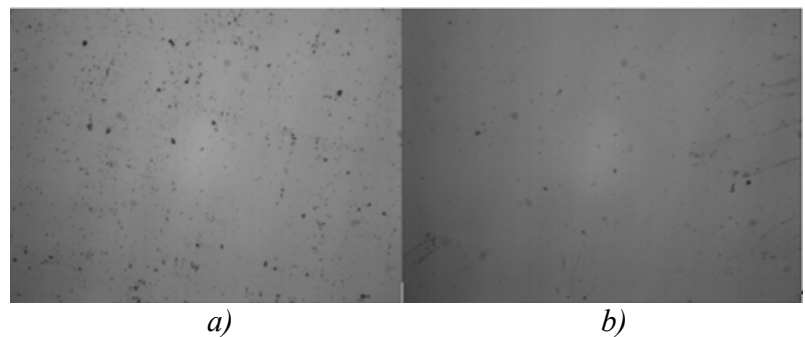

Fig. 1. Optical images of $\alpha$-Si films with yttrium: 1-2 (a), 1-3 (b).

images obtained using atomic force microscopy (AFM) gives more detailed information of surface film morphology (Fig. 2). There are some separate staying "needles" or "hills" on the film surface. This result seems to be very interesting because allows to assume that investigated films have nanocrystalline inclusions in their structure, which can be responsible for observed unique photoelectrical properties mentioned above.

\section{Raman spectroscopy results}

Raman spectroscopy is a sensitive instrument providing considerable information of the material structure based on $\alpha$-Si. In amorphous silicon, all phonons modes are active: longitudinal and transverse acoustic (LA, TA), as well as longitudinal and transverse optical ones (LO, TO) $[10,11]$. Thus, a comparative analyze of $\alpha$-Si based material Raman spectrum allows to discover some small changes in the short-range order. Raman spectra were measured at the wavelength $647.1 \mathrm{~nm}$ in non-polarized light using the $\mathrm{Kr}^{+}$Innova-300 laser. The reached resolution was $2.5 \mathrm{~cm}^{-1}$, illumination power $-15 \mathrm{~mW}$. It is seen from the Raman spectrum (Fig. 3) that $\alpha-\mathrm{Si}: \mathrm{Y}$ film is amorphous, because of the presence of a wide peak generated by TO mode within the range $200-$

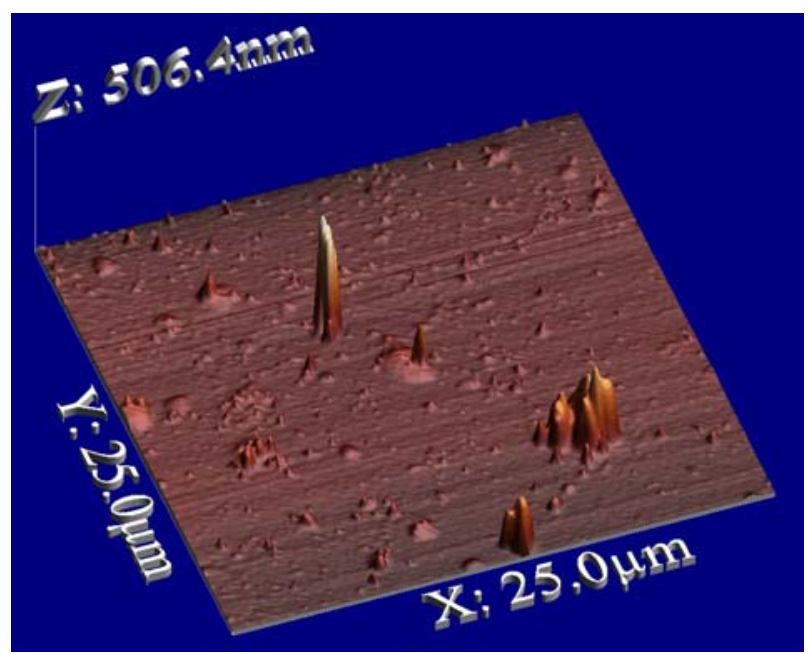

Fig. 2. AFM image of $\alpha-S i: Y$ film (sample 1-2). 
Table. Parameters of technological regimes.

\begin{tabular}{|c|l|c|c|c|c|}
\hline N sample & Target content & Substrate type & $\begin{array}{c}\text { Substrate temperature, } \\
{ }^{\circ} \mathrm{C}\end{array}$ & $\begin{array}{c}\text { Evaporator voltage, } \\
\text { kV }\end{array}$ & $\begin{array}{c}\text { Emission } \\
\text { current, } \mathrm{mA}\end{array}$ \\
\hline $1-1$ & $\alpha-\mathrm{Si}+10 \% \mathrm{Y}$ & $\mathrm{N}$ & 140 & 12 & 75 \\
\hline $1-2$ & $\alpha-\mathrm{Si}+10 \% \mathrm{Y}$ & $\mathrm{N}$ & 140 & 12 & 100 \\
\hline $1-3$ & $\alpha-\mathrm{Si}+10 \% \mathrm{Y}$ & $\mathrm{N}$ & 190 & 12 & 75 \\
\hline $1-4$ & $\alpha-\mathrm{Si}+10 \% \mathrm{Y}$ & $\mathrm{N}$ & 190 & 12 & 100 \\
\hline $1-5$ & $\alpha-\mathrm{Si}+10 \% \mathrm{Y}$ & $\mathrm{N}$ & 300 & 12 & 75 \\
\hline $2-1$ & $\alpha-\mathrm{Si}+10 \% \mathrm{Y}$ & $\mathrm{P}$ & 140 & 12 & 100 \\
\hline $2-2$ & $\alpha-\mathrm{Si}+10 \% \mathrm{Y}$ & $\mathrm{P}$ & 140 & 12 & 75 \\
\hline $2-3$ & $\alpha-\mathrm{Si}+10 \% \mathrm{Y}$ & $\mathrm{P}$ & 190 & 12 & 100 \\
\hline $2-4$ & $\alpha-\mathrm{Si}+10 \% \mathrm{Y}$ & $\mathrm{P}$ & 190 & 12 & 75 \\
\hline $2-5$ & $\alpha-\mathrm{Si}+10 \% \mathrm{Y}$ & $\mathrm{P}$ & 300 & 12 & 100 \\
\hline $2-6$ & $\alpha-\mathrm{Si}+10 \% \mathrm{Y}$ & $\mathrm{P}$ & 300 & & \\
\hline
\end{tabular}

$400 \mathrm{~cm}^{-1}$ with the full width of half maximum (FWHM) $100 \mathrm{~cm}^{-1}$. As this peak is not centered in the range of $480 \mathrm{~cm}^{-1}$ and its FWHM is larger than $70 \mathrm{~cm}^{-1}$, the structural perfection of the studied film is not suitable for device application [11]. It is known that nanocrystalline inclusions contribute to Raman spectrum a single sharp peak of TO mode with FWHM close to $4 \mathrm{~cm}^{-1}$ at the frequency of $520 \mathrm{~cm}^{-1}[11,12]$. However, this peak can not be observed at the grain size $\sim 3 \mathrm{~nm}$, or at the small nanocrystallite concentration. It could be also shifted to the frequency of $512 \mathrm{~cm}^{-1}$. TO modes of grain boundaries create a peak centered near $500 \pm 10 \mathrm{~cm}^{-1}$ [11]. Concerning the mentioned above information all the Raman spectra for all types of $\alpha$-Si:Y samples have the contribution from grain boundaries (small peak near $500 \pm 10 \mathrm{~cm}^{-1}$ ) and high structural defectiveness. The weakly pronounced peak in the range $512 \mathrm{~cm}^{-1}$ can be identified as a small amount of nanocrystalline inclusions in the film. The most intensive peak in the range $\sim 120 \mathrm{~cm}^{-1}$ is a response from the silicon substrate.

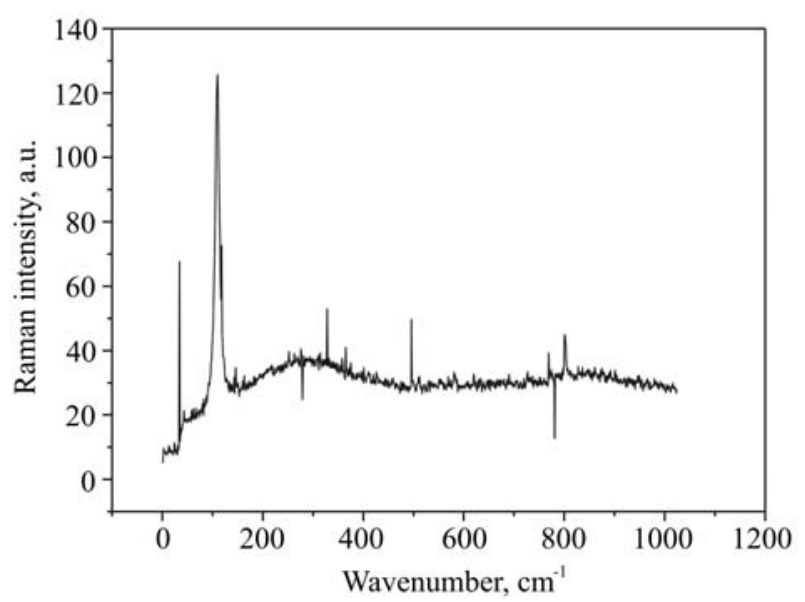

Fig. 3. Raman spectra of $\alpha$-Si:Y film (sample 2-4).

\subsection{Infrared spectroscopy}

The infrared (IR) spectroscopy measurements were carried out in the reflection regime at light incidence angle of $20^{\circ}$ using a Bruker IFS 66 Fourier Transform Infrared Spectrometer.

Generally, IR spectra of $\alpha$-Si:H consist of three absorption regions: at $630 \mathrm{~cm}^{-1}$ related to the $\mathrm{SiH}$ wag mode, a doublet at $850,890 \mathrm{~cm}^{-1}$ probably related to $\mathrm{SiH}_{2}$ bending modes, and the peaks at $2000-2090 \mathrm{~cm}^{-1}$ related to $\mathrm{SiH}$ stretching modes [13]. In the obtained $\alpha$ $\mathrm{Si}$ Y spectra (Fig. 4), there are the following modes: $\mathrm{Si}-\mathrm{H}_{\mathrm{x}}$ wagging mode at $650 \mathrm{~cm}^{-1}$ that is a typical characteristics [14] of hydrogen bonded to silicon; $\mathrm{C}$ at $790 \mathrm{~cm}^{-1} ; \mathrm{Si}-\mathrm{H}_{\mathrm{x}}$ bending scissors [14] mode at $890 \mathrm{~cm}^{-1}$; $\mathrm{SiO}$ at $1120 \mathrm{~cm}^{-1}$; a stretching mode of mono- and dihydrides [14] $\mathrm{SiH}, \mathrm{SiH}_{2}$ at $2125 \mathrm{~cm}^{-1}$; $\mathrm{SiHN}$ at $2250 \mathrm{~cm}^{-1} ; \mathrm{SiC}-\mathrm{NH}$ at $2800-3000 \mathrm{~cm}^{-1}$; $\mathrm{SiO}-\mathrm{H}$ stretching at $3760 \mathrm{~cm}^{-1}$ and $\mathrm{SiH}, \mathrm{SiH}_{2}, \mathrm{SiF}$ at $6000 \mathrm{~cm}^{-1}$. The peak at the frequency $2030 \mathrm{~cm}^{-1}$ assigned to siliconhydrogen clusters and known as platelet-like $\mathrm{SiH}$ group [5] is not observed. A peak containing information of yttrium presence in the film is not also identified. The $\alpha$ Si:Y films obtained at different technological regimes have the similar composition of vibration modes. But the intensity of peaks characterizing the mode concentration differs. IR spectrum peaks of films on $n$-Si indicate a bigger concentration of modes. As seen from IR spectra (Fig. 4), the type of substrates has a big influence on the structure of growing films. Thus, when deposing on the $p$-type substrate we observed the bigger growth rate $(\sim 0.1 \mu \mathrm{m} / \mathrm{min})$ and obtained the films with thicknesses 609, 658 and $735 \mathrm{~nm}$ (samples 2-2, 2-4 and 2-1, accordingly). The film thickness is determined from the interference fringes. At the same time, the inconsiderable growth rate and small thickness $\sim 100-$ $200 \mathrm{~nm}$ were obtained for $n$-Si substrates. It is possible to say that morphology and surface energy distribution of $p$-Si surface provides the better conditions for 

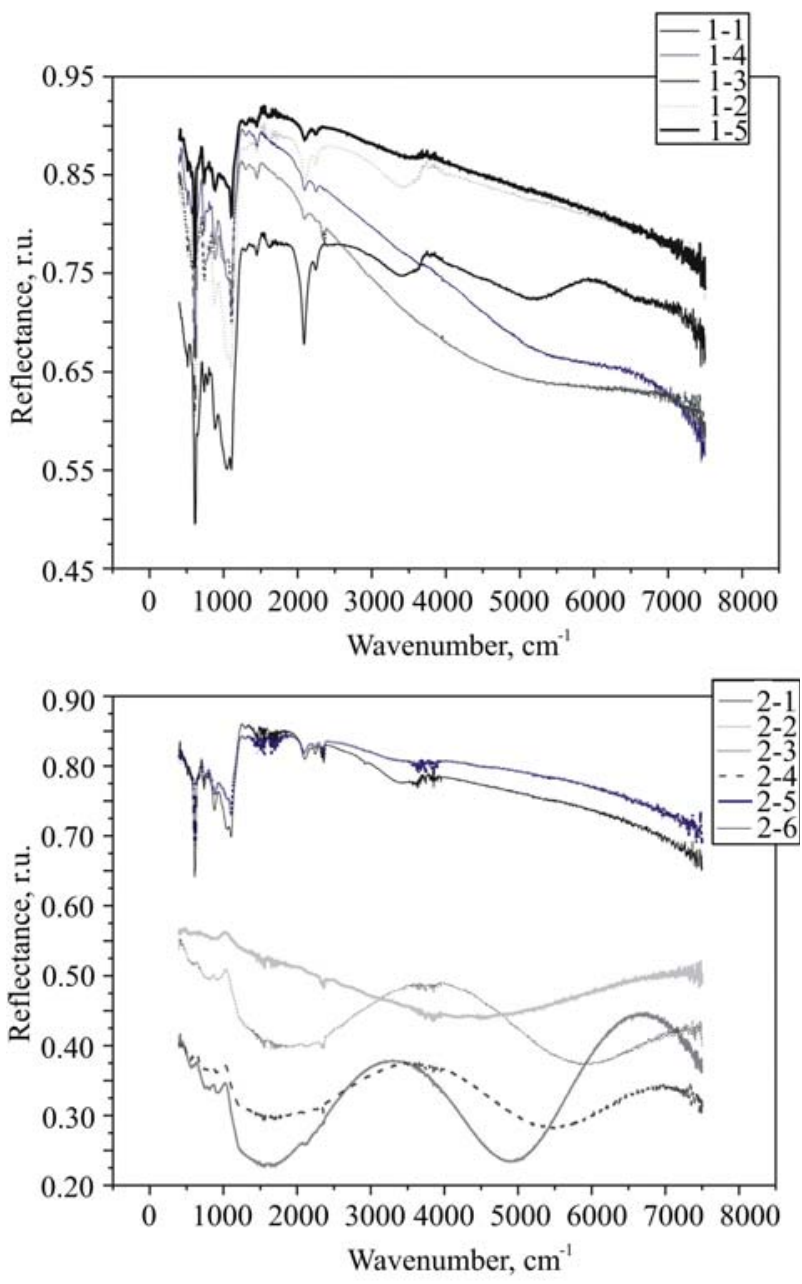

Fig. 4. The IR characteristics of samples deposited on $n$-Si (a) and $p$-Si (b).

nucleation and growth of $\alpha$-Si:Y films. The correlation between IR spectroscopy results and substrate temperature was not observed.

Thus, though the film deposition takes place in the process without $\mathrm{H}_{2}$, the films contain hydrogen in their composition. IR spectra have the peaks of the $\mathrm{SiH}_{2}$ complex that is known to play the main role in the nanocrystallization process [3]. Consequently, in our case, hydrogen also could create the centers stimulating crystallization in the course of growing the film. The bigger intensity of the peaks at the frequency $2125 \mathrm{~cm}^{-1}$ in the films deposited on $n$-Si specifies on the larger number of nanocrystalline inclusions. Therefore, the increased photosensitivity and degradation stability of our films has the ambiguous explanation. First variant is that yttrium creates the impurities levels increasing photosensitivity. Next reason is that nanocrystalline inclusions remove in part the mechanical stresses in amorphous matrix [7]. Thus, the less strained amorphous network with a lower concentration of weak bonds is formed. The obtained structure has less degradation under the illumination. But it is not clear what stimulates the nanocrystallization. The nanocrystalline inclusions could be formed either yttrium presence or due to $\mathrm{SiH}_{2}$ complexes.

\section{Ellipsometric results}

The optical constant measurements were performed using a spectro-ellipsometer VASE. The ellipsometric angles $\Psi$ and $\Delta$ were determined within the spectral range from 0.8 to $5.0 \mathrm{eV}$ at the angles of incidence 65 , 70 and $75^{\circ}$.

It was obtained that such important characteristic as the optical absorption is bigger for the $\alpha$-Si:Y films deposited on $n$-Si substrates in comparison with that of $p$-Si (Fig. 5). It correlates with IR spectroscopy results and confirms that films on $n$-Si have a higher concentration of various complexes forming impurity levels in the bandgap and resulting in increased absorption. The extinction coefficient $\kappa$ of $\alpha-\mathrm{Si}: \mathrm{Y}$ is less than the maximum value inherent to amorphous silicon $\kappa=3.0$ obtained from the reference database. The refraction coefficient $n$ changes within the range 3.4-1.7 under incident light frequencies $20000-37500 \mathrm{~cm}^{-1}$, which are also lower than values of amorphous silicon 4.5-2.05. These considerable changes of the refraction index is a disadvantage from the viewpoint of film application in solar cells and concede the refraction index stability reported in works $[12,15,16]$. However, the obtained value $n=3.4(\lambda=620 \mathrm{~nm})$ is close to the values $n=3.7(\lambda=600 \mathrm{~nm})$ demonstrated for $\alpha-\mathrm{Si}: \mathrm{H}$ films deposited by the chemical vapor deposition method [15] and the value $n=3.57(\lambda=700 \mathrm{~nm})$ for $\alpha$ $\mathrm{Si}: \mathrm{H}$ prepared by the glow discharge decomposition of the ammonia/silane gas mixture [16]. We obtained that the substrate temperature $T_{\text {sub }}$ and evaporation rate (emission current value) doesn't influence appreciably

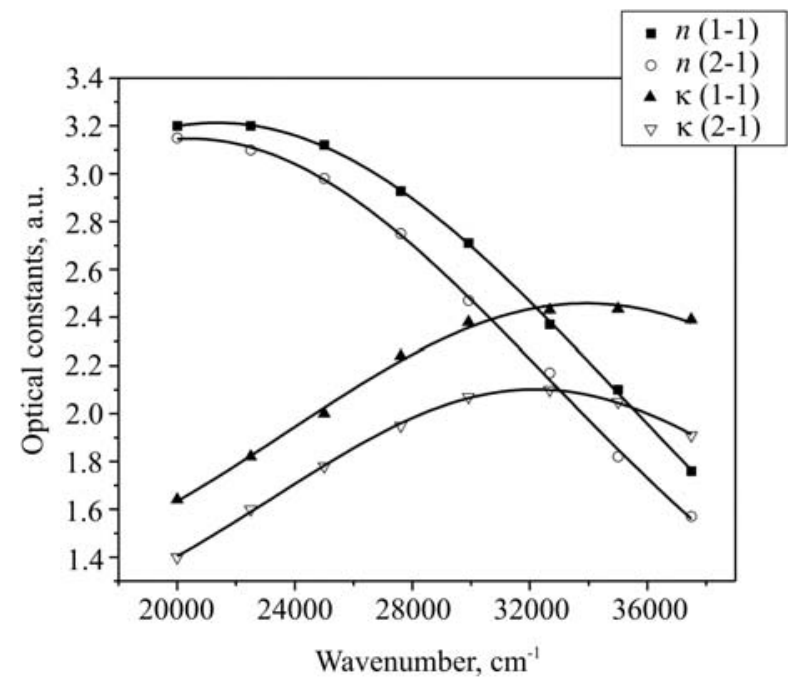

Fig. 5. Extinction coefficient $\kappa$ and refraction index $n$ of samples 1-1 and 2-1. 
on the refraction index. However, under the increasing substrate temperature, the optical bandgap width calculated in accord with the Tauc equation from the absorption coefficient dependence on the incident energy drops exponentially (Fig. 6). The value $E_{\mathrm{opt}}=1.51 \mathrm{eV}$ drops to value $1.17 \mathrm{eV}$ under changing the substrate temperature from 190 to $300{ }^{\circ} \mathrm{C}$. In work [15], it was obtained that samples $\alpha$-Si:H prepared at the substrate temperature $300{ }^{\circ} \mathrm{C}$ possess $E_{\text {opt }}=1.55 \mathrm{eV}$ that drops to $1.17 \mathrm{eV}$ after annealing at $500^{\circ} \mathrm{C}$. A.V. Nejdanov et al. explain the optical bandgap decrease after annealing by the fact of film structural disordering. Though, in principle, the annealing should lead to defect concentration reduction and increase of the bandgap width. Originally, on the base of work [3] we assumed that $\alpha$-Si:Y films deposited under substrate temperature $300{ }^{\circ} \mathrm{C}$ would have the minimal number of defects. Thus, the films $\alpha-\mathrm{Si}: \mathrm{H}$ deposited at $T_{\text {sub }}=120^{\circ} \mathrm{C}$ have the defect density of $10^{19} \mathrm{~cm}^{-3}$, and films deposited at $T_{\text {sub }}=250^{\circ} \mathrm{C}$ have $10^{15} \mathrm{~cm}^{-3}$ [3]. Undoubtedly that the substrate temperature considerably influence on the structure of growing films and consequently on the films optical characteristics. Possibly, under the substrate temperature increase the film structural disordering occurs. Another explanation that in the case of higher temperatures the bigger amount of impurity levels in the bandgap forms. In work [1], the bandgap width decrease is explained by increasing of the nanocrystalline phase part. This idea is confirmed by our results. Thus, the sample 1-1 possessing the most intensive $\mathrm{SiH}_{2}$ peak in the IR spectrum has the optical bandgap width $1.75 \mathrm{eV}$ that is higher than values of all another samples with less intense $\mathrm{SiH}_{2}$ peaks. There is also remarkable influence of the evaporation rate on the $E_{\text {opt }}$ value. As a rule, the growth rate increase is a desirable effect for thin film deposition because of economical reasons in their further application. Moreover, it is known [3] that the defect

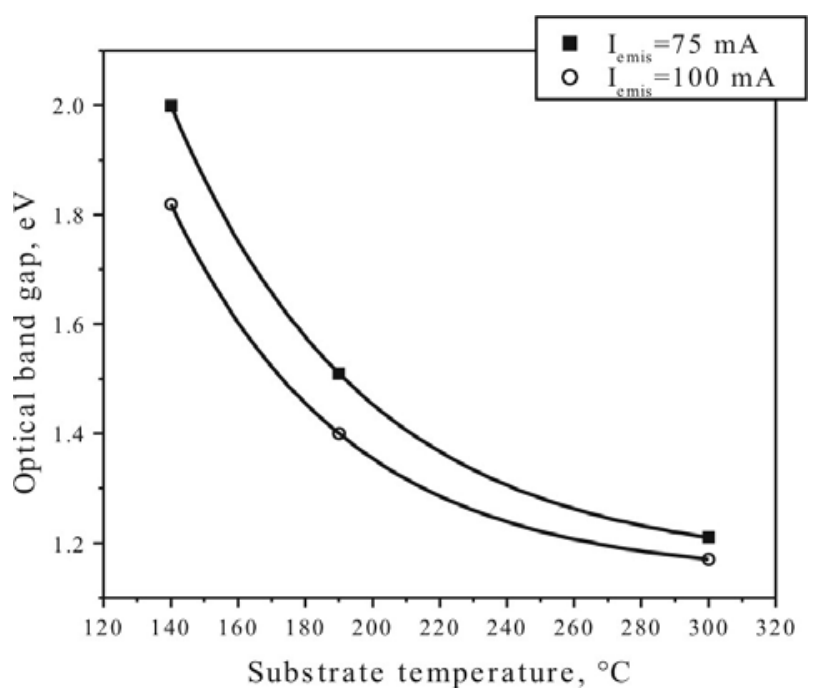

Fig. 6. Optical bandgap dependence on the substrate temperature for films deposited on $p$-Si. density in the growing film could be decreased in the case when the growth rate is higher than the rate of hydrogen motion in the substrate and hydrogen-leaving rate from the growing film. However, in our case it is obvious (Fig. 6) that with an increase in emission current and, consequently, in the growth rate, the optical bandgap width decreases and the forming film is more structurally disordered.

\section{Conclusions}

As a result of investigation, it is obtained that $\alpha-\mathrm{Si}: \mathrm{Y}$ films deposited by electron-beam evaporation have the amorphous structure with small amount of nanocrystalline inclusions that was demonstrated by AFM. Instead of the fact that the hydrogen is absent in the course of the deposition process, the $\alpha-\mathrm{Si}: \mathrm{Y}$ films possesses the $\mathrm{SiH}_{2}$ phase in its composition, which could be crystallization centers during the growth. Under the increase of the substrate temperature to $300{ }^{\circ} \mathrm{C}$, the optical bandgap width drops from 2.0 to $1.17 \mathrm{eV}$. It is assumed that at the temperature $300{ }^{\circ} \mathrm{C}$ the structure of the growing film is more disordered.

Because of the small concentration of nanocrystalline inclusions demonstrated by the weakly pronounced peak $\sim 512 \mathrm{~cm}^{-1}$ in the Raman spectrum, nanocrystallites could not considerably influence on the change of $E_{\text {opt }}$. The obtained coefficients of extinction $\kappa$ and refraction index $n=3.2-3.4$ inherent to $\alpha-\mathrm{Si}: Y$ films are less than those of pure $\alpha-\mathrm{Si}$. The emission current increase enables to increase the growth rate of $\alpha$-Si:Y films deposited on the $p$-type substrate to $\sim 0.1 \mu \mathrm{m} / \mathrm{min}$. However, the increase of the growth rate also leads to bigger film structural disordering. Being based on the fact that the photosensitivity and stability of electrical characteristics of $\alpha-\mathrm{Si}: \mathrm{Y}$ films is very high and the films themselves are absolutely new investigated object, we consider that determination of yttrium impact on the film composition and answer on the question what is responsible for the increase in photosensitivity are perspective directions for future investigations.

\section{Acknowledgement}

The author would like to thank to Dr. A. N. Smyryeva and M. G. Dusheyko (NTUU "KPI", Kiev, Ukraine) for sample preparation, to Prof. V.G. Litovchenko (Institute of Semiconductor Physics, Kiev, Ukraine) for assistance in interpretation of the IR spectra, M. Rommel (TU Erlangen-Nurenberg, Germany) for AFM measurements, Prof. D. Zahn and Dr. M. Friedrich (TU Chemnitz, Germany) for their help in simulation of calculations after ellipsometric measurements.

\section{References}

1. V.P. Afanas'ev, A.S. Gudovskikh, O.I. Kon'kov, M.M. Kazanin, K.V. Kougiya, A.P. Sazanov, 
I.N. Trapeznikova, and E.I. Terukov // Semiconductors 34(4), p. 477-480 (2000).

2. M.A. Green, Crystalline and thin-film silicon solar cells: state of the art and future potential // J. Solar Energy, 74(3), p. 181-192 (2003).

3. A. Matsuda, Thin film silicon growth process and solar cell application // Jpn J. Appl. Phys. 43(12), p. 7909-7920 (2004).

4. V.P. Afanas'ev, A.S. Gudovskikh, V.N. Nevedomski, A.P. Sazanov, A.A. Sitnikova, I.N. Trapeznikova, and E.I. Terukov, Effect of thermal treatment on structure and properties of a-Si:H films obtained by cyclic deposition // Semiconductors 36(2), p. 230234 (2002).

5. O.A. Golikova and M.M. Kazanin, Special features of photoelectric properties of nanostructured films of hydrogenated silicon // Semiconductors 35(10), p. 1187-1190 (2001).

6. O.A. Golikova, Photoconductivity of nanostructured hydrogenated silicon films // Semiconductors 36(6), p. 691-694 (2002).

7. V.P. Afanasiev, A.S. Gudovskikh, A.Z. KazakKazakevich, A.P. Sazanov, I.N. Trapeznikova, and E.I. Terukov, TEM study of the formation and modification of nanocrystalline $\mathrm{Si}$ inclusions in aSi:H films // Semiconductors 38(2), p. 221-224 (2004).

8. A.N. Shmyryeva, T.V. Semikina, M.G. Dushejko, N. Bishena, Thin films of silicon-yttrium alloys // Book of Abstracts. Russian Symposium of Amorphous and Single Crystal Semiconductor, May-June, St-Petersburg, p. 144 (1998) (in Russian).

9. A.N. Shmyryeva, T.V. Semikina, M.G. Dushejko, Thin films of amorphous silicon-yttrium alloys // Book of Abstracts of Second Russian Conference
(“Silicon-2000”), Moscow, February 9-11, 2000, p. 374-376 (in Russian).

10. J.E. Gerbi, P.M. Voyles, M.M.J. Treacy, J.M. Gibson, J.R. Abelson, Increasing medium-range order in amorphous silicon with low-energy ion bombardment // J. Appl. Phys. Lett. 82(21), p. $3665-$ 3667 (2003).

11. Daxing Han, J.D. Lorentzen, J. Weinberg-Wolf, L.E. McNeil, Qi Wang, Raman study of thin films of amorphous to microcrystalline silicon prepared by hot-wire chemical-vapor deposition // J. Appl. Phys. 94(5), p. 2930-2936 (2003).

12. O.A. Golikova and M.M. Kazanin, Effect of nanocrystalline inclusions on the photosensitivity of amorphous hydrogenated silicon films // Semiconductors 34 (6), p. 737-740 (2000).

13. Daxing Han, Keda Wang, Jessica M. Owens, Lynn Gedvilas, Brent Nelson, Hotoe Habuchi, Masako Tanaka, Hydrogen structures and the optoelectronic properties in transition films from amorphous to microcrystalline silicon prepared by hot-wire chemical vapor deposition // J. Appl. Phys. 93(7), p. 3776-3783 (2003).

14. A.H.M. Smets, W.M.M. Kessels, M.C.M. van de Sanden, Vacancies and voids in hydrogenated amorphous silicon // J. Appl. Phys. Lett. 82(10), p. 1547-1549 (2003).

15. A.V. Nezhdanov, A.I. Mashin, A.F. Khokhlov, V.G. Shengurov, A.K. Yezhov Optical properties of structural heterogeneous silicon // Abstract book of IV International Conference on Amorphous and Microcrystalline Semiconductors, 5-7 July, St. Petersburg, Russia (2004) (in Russian).

16. Ilker Ay, Husein Tolukay, Optical transmission measurements on glow-discharge amorphous-silicon nitride films // Turk. J. Phys. 25, p. 215-222 (2001). 